Mila R. Samardžić

\title{
O NASTANKU I RAZVOJU SISTEMA FINALNIH VEZNIKA U ITALIJANSKOM JEZIKU
}

\begin{abstract}
U ovom radu prikazali smo nastanak i razvoj finalnih veznika i vezničkih izraza u italijanskom jeziku. Nastojali smo da utvrdimo da li se ova vrsta veznika razvijala u skladu sa opštim tendencijama u italijanskom vezničkom sistemu: od malobrojnih nasleđenih iz latinskog jezika preko stvaranja mnoštva novih složenih oblika i izraza u srednjem veku ka smanjivanju broja jedinica od renesanse do današnjih dana. Razmotren je i podatak o postojanju relativno malog broja finalnih veznika u odnosu na ostale veznike koji određuju srodne uzročno-posledične odnose. Istraživanje je sprovedeno na uzroku koji obuhvata književne spomenike na italijanskom jeziku od njegovih početaka do danas. Poseban naglasak stavljen je na razvoj sistema u 13, 14. i 16. veku, ključnim razdobljima u italijanskom jeziku uopšte. Rezultati su pokazali da se sistem finalnih veznika u izvesnoj meri poklapa sa opštim vezničkim sistemom ali da, ipak, pokazuje izvesnu posebnost u pogledu znatno manjeg broja jedinica i manje učestalosti u poređenju sa uzročnim, pogodbenim, dopusnim i posledičnim veznicima.
\end{abstract}

Ključne reči: veznici, finalnost, uzročnost, italijanski jezik, sintaksa, dijahronija.

\section{Uvod}

Finalne ili ciljne zavisne rečenice u italijanskom jeziku mogu se koristiti u dva oblika: eksplicitnom, s predikatom ciljne rečenice u konjunktivu prezenta ili imperfekta, ili implicitnom, s predikatom u infinitivu. U ovom radu analiziraćemo nastanak i istorijski razvoj finalnih veznika koji uvode eksplicitne rečenice. Pošli smo od pretpostavke da se sistem finalnih veznika u italijanskom jeziku razvijao u skladu sa opštim tendencijama u nastanku italijanskog vezničkog sistema i promenama koje su se u nje-

Filološki fakultet, Studentski trg 3, 11000 Beograd, elektronska pošta:

milasamardzic@fil.bg.ac.rs. 
mu ostvarile (Samardžić, 2003; Rombi, Policarpi, 1985: 239): u srednjem veku sistem je doživeo veliko bogaćenje da bi, od renesanse (a u skladu s težnjom ka ujednačavanju i sistematizaciji čitave gramatike), počeo da se pojednostavljuje. Naime, posmatrajući istorijski razvoj veznika, utvrđeno je da je smanjen broj leksičkih i fonoortografskih varijanti, kao i gubitak određenog broja leksema: od registrovanih 525 oblika u 13. i 14. veku, danas je u upotrebi oko 290 oblika. Isto tako, utvrđeno je da razvojem jezika, od 16. veka, nije došlo do nastanka novih veznika već samo vezničkih izraza (Samardžić, 2003: 277).

Međutim, zanimljiva je činjenica da se, i bez neke detaljnije analize, lako uočava da postoji relativno mali broj oblika finalnih veznika u odnosu na druge zavisne veznike koji označavaju neki uzročno-posledični odnos. Na primer, u staroitalijanskom jeziku utvrdili smo upotrebu oko 40 oblika uzročnih veznika i vezničkih izraza (naspram današnjih 20), oko 30 pogodbenih (naspram današnjih dvadesetak), 14 posledičnih (naspram današnjih 11), 27 koncesivnih (naspram današnjih 14) itd. U obimnom korpusu uočili smo desetak oblika (što u starom što u savremenom jeziku) s tim što samo jedan od njih ima isključivo finalnu vrednost (affinché, ako izuzmemo novije izraze allo scopo che, coll' (nell') intenzione che, a far si che koji se i danas retko upotrebljavaju). Jedan od uzorka za manji broj finalnih konektora svakako je češća upotreba ovih rečenica u implicitnom nego u eksplicitnom obliku. Budući da su implicitne ciljne rečenice bliže duhu italijanskog jezika, u slučajevima kada se subjekti upravne i namerne rečenice ne podudaraju (što je neophodan uslov za implicitni oblik), moguća je transformacija eksplicitne u implicitnu rečenicu upotrebom kauzativnih glagola: [io] Dico a bassa voce perché [loro] non mi sentano. > Dico a bassa voce per non farmi sentire; È veramente un peccato che il paese più potente del mondo abbia speso tanti soldi perché le sue menti migliori studiassero, e poi non le stia ad ascoltare. $>$ E veramente un peccato che il paese più potente del mondo abbia speso tanti soldi per far studiare le sue menti migliori, e poi non le stia ad ascoltare. Implicitna konstrukcija sa subjektom različitim od subjekta upravne rečenice moguća je i ukoliko se subjekat namerne rečenice podudara sa indirektnim ili direktnim objektom upravne rečenice: Il padre ha incitato i figli a studiare di più.

Prednost koja se daje upotrebi implicitnih oblika može se objasniti i nužnom upotrebom konjunktiva u eksplicitnom obliku: ta upotreba podrazumeva, s jedne strane, dalekosežno planiranje diskursa (Berretta, 1984) 
a, s druge strane, ne doprinosi lepoti izlaganja budući da deluje prilično izveštačeno. U prilog tome govori i činjenica da se, za razliku od ostalih subordinativnih rečenica, u finalnim, u slučaju podudaranja subjekta u upravnoj i podređenoj rečenici, nikada ne koristi eksplicitni oblik (*Lavorano perché guadagnino di più. Lavorano per guadagnare di più; dok je ravnopravno prihvatljiv i jedan i drugi oblik, na primer, u uzročnim rečenicama: È contento perché ha vinto il concorso. È contento per aver vinto il concorso).

\section{Ciljevi rada i jezički uzorak}

U ovom radu pratićemo razvoj sistema finalnih veznika od prvih pisanih spomenika na narodnom jeziku do savremene jezičke situacije. Nastojaćemo da prikažemo nastanak i tendencije u razvoju sistema. Utvrdićemo da li i u ovom sistemu, poput drugih, dolazi do smanjenja broja jedinica u upotrebi i do njegovog pojednostavljivanja ne samo na fonoortografskom i leksičkom već i sintaksičkom nivou.

Imajući u vidu ciljeve ovog rada i primenjeni pristup, analizirali smo upotrebu finalnih veznika u unapred određenom korpusu. ${ }^{1}$ Budući da je istraživanje zasnovano na istorijskom proučavanju jezika, ono je jednim delom ograničeno na dati odnosno zatvoreni korpus (Kristal, 1988: 135) zbog prirodne nemogućnosti njegovog proširivanja. Analizirani jezički materijal obuhvata period od prvih pisanih spomenika na italijanskom jeziku do savremenog jezika. Za stariju jezičku fazu ograničili smo se na književne tekstove pisane tradicije. Pored njih, uzeli smo u obzir dela praktičnog karaktera, kao

1 U radu se prilikom davanja primera iz dela proznog karaktera, navode ime autora i/ ili dela (često skraćeno), rimski broj koji označava poglavlje (ili pasus odnosno deo poglavlja) i/ili strana u novijim izdanjima. Za primere iz poezije navode se ime autora i/ili dela (često skraćeno), rimski broj koji označava broj poetskog sastava (na primer, broj pesme u Petrarkinom Kanconijeru, ili broj pevanja, u Božanstvenoj komediji) i arapski broj koji označava broj stiha. Danteova dela na narodnom jeziku analizirana su iz šestog toma enciklopedije Enciclopedia Dantesca, u kome su sadržana sva Danteova dela. Skraćenice za pojedinačna dela: $\mathrm{VN}=$ Vita Nuova, IF $=$ Inferno, $\mathrm{PG}=$ Purgatorio, $\mathrm{PD}=$ Paradiso, $\mathrm{CV}=$ Convivio. Napominjemo da je znatan broj primera preuzet iz velikog istorijskog rečnika italijanskog jezika S. Batalje. Za te kao i za primere iz Danteovih dela nismo posebno navodili izvore u spisku literature. 
što su hronike, istorije, politička, religiozna i naučna dela, koja su ponekad bliža govornom jeziku te nam donekle mogu pomoći u njegovoj rekonstrukciji. Sintaksičke i semantičke promene finalnih veznika i vezničkih izraza utvrđivane su na osnovu poređenja tekstova od 13. i 14. veka (prevashodno, Novelina, prvih pesničkih škola, Danteovih, Petrarkinih i Bokačovih dela na narodnom jeziku) s delima autora moderne epohe italijanskog jezika $\mathrm{i}$ književnosti (19. i 20. vek), uz poseban osvrt na autore 16. veka (naročito Makijavelija, Gvičardinija, Čelinija, Bemba, Ariosta i Tasa). U radu je, u skladu s prostornim mogućnostima, naveden samo ograničen broj primera.

Finalne rečenice u italijanskom jeziku iskazuju cilj koji pokreće radnju upravne rečenice. Smatra se jednim od načina ostvarivanja logičkih odnosa. Naime, između dve rečenice moguće je uspostaviti uzročno-posledični odnos pomoću istog veznika koji uvodi uzročne rečenice, s razlikom u upotrebi načina: L'ho invitato perché anche lui è al corrente. L'ho invitato perché anche lui sia al corrente (primeri preuzeti iz Bertuccelli Papi, 1991: 818). U prvoj rečenici iskazan je stvaran uzrok izvršenja radnje upravne rečenice i on joj logički prethodi (kao činjenično stanje). U drugom primeru finalna rečenica perché anche lui sia al corrente iskazuje isti razlog čije ostvarenje treba da usledi posle radnje iskazane u upravnoj rečenici, a ono pritom ne mora biti potpuno izvesno. Dakle, finalnost je blisko povezana sa uzročnošću. Kao i kod uzročnog odnosa, postoje uzrok i posledica koja zavisi od uzroka i od koje zavisi njeno ispunjenje. Ipak, dok kod uzročnosti uzročna okolnost predstavlja aktivni kvalitet, kod finalnosti posledica predstavlja pokretačku snagu koja objašnjava ostvarivanje uzroka. O finalnim rečenicama i iskazivanju finalnosti u italijanskom jeziku objavljeno je nekoliko značajnih studija (Greco Bolli, 1982; Bertuccelli Papi, 1991; Prandi, 1995; Prandi, Gross i dr., 2005; Pantiglioni, 2010;) tako da se nećemo zadržavati na njihovim opštim karakteristikama već ćemo se usredsrediti na finalne veznike.

Finalni veznici i veznički izrazi u italijanskom jeziku uvode podređene rečenice sa obaveznom upotrebom konjunktiva (prezenta ili imperfekta). Ova ograničena upotreba vremena i isključivo jednog načina objašnjava se logičnom nemogućnošću da cilj prethodi radnji iskazanoj u upravnoj rečenici: između radnji upravne i podređene rečenice postoji uzročni logički odnos koji željeni cilj smešta u budućnost. Ishod takvog logičkog odnosa isključuje mogućnost upotrebe indikativa u finalnoj implicitnoj rečenici budući da cilj još nije ostvaren u vremenu iskazanom u upravnoj rečenici. Upotreba indi- 
kativa kao načina koji odražava stvarnost u izražavanju ovakvog logičkog odnosa ne bi bila prikladna. ${ }^{2}$ Međutim, još jedan važan razlog što italijanski finalni veznici uvek uvode rečenicu s predikatom u konjunktivu leži u njihovoj nedovoljnoj određenosti. Naime, svi italijanski finalni veznici jesu polivalentni veznici i koriste se za uvođenje i nekih drugih zavisnih rečenica. Stoga upotreba konjunktiva ukazuje na njihovu finalnu vrednost. Jedini izuzetak je veznik affinché koji ima isključivo finalnu vrednost, ali se njegova upotreba beleži sa zakašnjenjem u odnosu na druge oblike. Stoga se može zaključiti da u eksplicitnim finalnim rečenicama konjunktiv ne predstavlja, kao što je to slučaj sa ostalim zavisnim rečenicama, morfološko obeležje podređenosti, koje se odnosi na upotrebu određenog veznika bez modalne vrednosti (D’Arienzo, Frenguelli, 2012: 370). Upravo u rečenicama u kojima je upotreba veznika obavezna uočava se možda veća uloga načina nego samog veznika. U primerima u kojima isti veznik uvodi dve različite vrste podređenih rečenica (Lavoro perché guadagno molto. vs. Lavoro perché tu viva meglio) način je taj koji određuje razliku između uzročne i finalne rečenice. S druge strane, neki autori (Agostini, 1978: 379, Ageno, 1978: 249) upravo tom velikom semantičkom težinom konjunktiva objašnjavaju kašnjenje u pojavi prvoj isključivo finalnog veznika: „quasi che la presenza del congiuntivo, con la sua componente volitiva e possibilistica potesse garantire in assoluto la chiarezza del nesso logico e del legame sintattico subordinativo" (D’Arienzo, Frenguelli, 2012: 370).

\section{Poreklo i razvoj italijanskih finalnih veznika}

Kao što smo to već konstatovali (Samardžić, 2003: 35), samo mali broj italijanskih veznika direktno je nasleđen iz latinskog jezika, dok je veći deo sistema sačinjen od modifikovanih ili novonastalih oblika. ${ }^{3}$ Pretpostavlja se da je već govorni latinski jezik zanemarivao i odbacivao brojne nijanse i mogućnosti kojima je raspolagala bogata gramatika klasičnog latinskog jezika.

2 Upotreba konjunktiva u finalnim rečenicama bila je dosledna i u latinskom jeziku. Ova konstrukcija upotrebljavala se po obrascu $u t+$ konjunktiv.

3 Sačuvana je osnovna podela na koordinativne i subordinativne veznike, ali veliki broj latinskih veznika nije uspeo da se zadrži u italijanskom jeziku verovatno zbog širenja upotrebe paratakse (koja je u osnovi govornog jezika) i nepopularnosti oblika koji su se zadržali isključivo u pisanoj tradiciji (Tekavčić, 1972:859). 
O tome svedoče primeri iz tekstova koji pripadaju nižim jezičkim registrima, kao i činjenica da je najveći broj veznika u italijanskom jeziku nastao razvojem jezika, tj. samo mali broj je direktno nasleđen iz književnog latinskog jezika. Najznačajniji deo italijanskog vezničkog sistema predstavljaju novi perifrastični oblici (Mancarella, 1978: 119) nastali u govornom jeziku od imenica, zamenica, priloga, predloga, glagola i prideva, i to najčešće u kombinaciji s već široko rasprostranjenim che (Tekavčić, 1972:908: „quod tuttofare”).

Che (ché). Staroitalijanski nastavlja tendenciju govornog kasnolatinskog čuvanjem polivalentnosti veznika che. Još od prvih primera, veznik che s finalnom vrednošću, uvodi rečenicu s predikatom u konjunktivu (Giacomo da Lentini I 73: Vorria c'or avvenisse / a lo meo cor ch'escisse / come ncarnato tutto, / e non dicesse mutto - a voi, sdegnosa). Njegova upotreba bila je široko rasprostranjena u staroj prozi. Na primer, u Novelinu u istoj meri je zastupljen kao veznici perché i acciò che, a i Bokačo ga je koristio u Dekameronu (Novellino XCII: Corruppero uno de' maggiori cavalieri della corte del re, per pregio e per prezzo, ch'elli per questo modo ordinasse della morte del garzone; Decameron IX 6 27: Torna qua, che Dio ti dea la mala notte!). Uvek uvodi rečenicu u postpoziciji u odnosu na upravnu rečenicu (Machiavelli 779: L'uomo è solo creato per bene e onore d'Iddio; al quale die' il parlare, ché potessi laudarlo). Najčešće ga uvode glagoli pregare, chiedere, impedire, procurare, badare ili izrazi sa sličnim značenjem (Greco Bolli, 1982:136-137, Vagni, 1974:330, Herczeg, 1972:373): VN XVIII 6: Noi ti preghiamo che tu ne dichi ove sta; Cellini 26: Stupefatto non sapeva trovare rimedio, che quel velenoso animale non mi uccidesse. Che, koje uvode izrazi fare in modo, ili glagoli fare i guardare (u značenju ,stare attento”, „fare attenzione”), ima vrednost koja je na granici između finalne i posledične (PG II 28: Fa, fa che le ginocchia cali: / ecco l'angel di Dio: piega le mani: / omai vedrai di sì fatti officiali; PG XVI 15: Guarda che da me tu non sia mozzo). U staroitalijanskom jeziku zabeležili smo i pojavu elipse finalnog che (Petrarca XCII 6: Io per me prego il mio acerbo dolore, / non sian da lui le lagrime contese). U savremenom jeziku daleko manje se koristi od uzročnog che, a po Serijaniju, uvek je obeležen grafičkim akcentom (Serianni, 1988: 490: Dietro questo pensiero, più visione che pensiero, c'era sommessa, nascosta, ché il capitano non gliela scoprisse, la preoccupazione che non aveva mangiato in caserma).

Come. Prelaz od komparativnog do finalnog $u t \mathrm{u}$ latinskom odgovara upotrebi come (od rasprostranjenog kasnolatinskog veznika quomodo) u staroitalijanskom (Giacomo da Lentini: Io m'aggio posto in core a Dio servire, 
/ com 'io potesse gire in Paradiso, /lo santo loco, ch'aggio audito dire / u'si mantien sollazzo, gioco e riso). Ova finalna upotreba veznika come rano se izgubila i u potpunosti je nestala u savremenom italijanskom jeziku.

Onde. Pored vremenske i posledične, latinski upitni prilog za mesto onde u staroitalijanskom dobio je i finalnu vrednost (PG XXII 142: Più pensava Maria onde / fosser le nozze orrevoli ed intere, / ch'a la sua bocca). Osim eksplicitnih s glagolom u konjunktivu, uvodi i implicitne rečence s glagolom u infinitivu. Bio je u upotrebi s tom vrednošću još od najstarijih dokumenata, pogotovu u poeziji. Naime, elegantne i kratke forme, za razliku od perché, a pogotovu acciò che, bio je daleko prikladniji ovom jezičkom izrazu (Ariosto XII 46: Trasse la spada, e in atto si raccolse, / onde con essa e col levato scudo / potesse ricoprirsi il capo nudo). Međutim, u 19. veku ovakva upotreba onde doživela je osudu purista: „Il marchese Basilio Puoti avrebbe attaccato un cartello nella stanza in cui faceva lezione con la scritta: Chi usa onde in iscambio di affinché o di per è solenne ciuco" (Fanfani-Arlia, 1881:326). Bez obzira na kritike, ovaj veznik zadržao se s finalnom vrednošću, ali gotovo isljučivo u pisanom jeziku (Saba 153: Mi chiami onde in gran fretta si vada / qualche passo più in là sull'ampia terra).

\section{Veznički izrazi kao novonastali oblici}

Paralelno s opštim razvojem jezika i veznički sistem doživljava ekspanziju počev od 12. veka. Kod velikih autora to bogaćenje se ispoljavalo pod uticajem sintaksičkih modela koji su postojali u klasičnom latinskom jeziku. Novonastali veznički izrazi mogu se grupisati u dve kategorije: prvu grupu predstavljaju veznici u čiji sastav ulazi veznik che, a drugu veznici dobijeni pomoću nekog drugog veznika (come, quando itd).

Veznički izrazi s che nastali su ili direktnim spajanjem predloga ili priloga za veznik, ili dodavanjem nekog pronominalnog elementa.

Perché. U svim italijanskim dijalektima postoji u nekom obliku veznik perché (per + che) i to još od prvih književnih tekstova (Latini Rettor. 62-23: Il ladro ee da 'mpendre, perché commette furto). Ovaj veznik imao je pre svega uzročnu vrednost (Novellino XXXV: Rimurarono mezzo l'uscio d'uno loro palagio dove si riduceano, perché non v'entrasse; CV I X 14: Di ciò farò [...] speziale capitolo, perché più notevole sia la loro infamia). U pr-

vim književnim dokumentima na narodnom jeziku daleko ređe je izražavao 
finalnost. Tako retka finalna upotreba vezničkih izraza konstruisanih s predlogom per može se objasniti postojanjem starog i veoma rasprostranjenog finalnog izraza acciò che.

Finalne rečenice koje je uvodio veznik perché nisu imale obavezan položaj u rečenici. Mogle su da stoje ispred nadređene rečenice (Decameron VIII 7 71: Perché il giorno quivi non la cogliesse, cominciò a volere smontare), kao i iza nje (Decameron VII 8 18: Tu hai spento il lume perché io non ti truovi). Ipak, uobičajeni položaj bio je iza nadređene rečenice (Novellino XCII: Il mandò al servizio d'un re, perché egli apparasse ivi gentilezza e nobili costumi; Decameron IX 9 17: Lo incominciò a battere perché 'l parlasse). ${ }^{4}$ Finalno perché moglo je da stoji u korelaciji s nekim drugim finalnim veznikom tvoreći tako konstrukciju s dve finalne rečenice međusobno koordinirane (Decameron X C 6: Acciò che per troppa lunga consuetudine alcuna cosa che in fastidio si convertisse nascer non ne potesse, e perché alcuno la nostra troppo lunga dimoranza gavillar non potesse [...] giudicherei [...] che convenevole cosa fosse omai il tornarci là onde ci partimmo). Prelazni uzročno-finalni tip perché može se naći u slučajevima kad se u nadređenoj rečenici nađe neki od glagola koji izražavaju „molbu” (pregare, supplicare) ili „opomenu” (guardare, star attenti): Decameron VI 10 4: Né vi dovrà esser grave, perché io [...] alquanto in parlar mi distenda. Takve rečenice ne izražavaju direktno sadržaj poruke (objekat), već cilj radnje sadržan u poruci, tako da bismo ovo perché pre mogli svrstati u finalno. ${ }^{5}$

U savremenom italijanskom jeziku perché je najkorišćeniji finalni veznik u svim registrima, kao i uzročni veznik istog oblika. U vreme Dantea i Bokača, acciò che je bio glavni finalni veznik. Primećuje se da se vremenom širi upotreba finalnog perché, dok affinché počinje da se koristi tek sredinom 14. veka. Budući da su i acciò che i perché mogli uvoditi i uzročne rečenice, finalne konstrukcije su imale obaveznu upotrebu konjunktiva koja je nasle-

$4 \quad$ Up. Samardžić, 1988:239-240: „La prolessi è per lo più legata a motivazioni affettive o retoriche che spingono l'autore a esprimere anticipatamente lo scopo di ciò che sta per dire; essa è infatti particolarmente frequente nel dialogo e nel racconto quando il parlante coincide col soggetto della volontà. [...] l'uso della prolessi serve a rompere l'ordine 'logico' e ad anteporre l'enunciazione del 'fine', che è il fatto che riguarda più da vicino l'interlocutore. [...] l'anticipazione del fine sembrerebbe avere la funzione di richiamare l'attenzione di chi legge o ascolta prima che la comunicazione sia espressa".

5 Postoji još jedan slučaj kad perché uvodi uzročne rečenice sa konjunktivom, ali koje se mogu tumačiti i kao finalne: Lidia lavora tanto perché $i$ suoi figli abbiano un futuro migliore (Renzi, Salvi 1991:742) 
đena iz latinskog jezika. Vezniku perché je davano više prostora u poeziji zbog elegancije, jednostavnosti i, možda, dvosmislenosti, dok se acciò che više koristilo u prozi zbog jasnoće i preciznosti (Samardžić, 1998: 239).

Acciò che (i varijante acciocché, a ciò che) jeste veznički izraz koji je sigurno postojao od prvih tekstova koji su nastali na narodnom jeziku. Javio se u mnogim dijalektima s finalnom, ali i sa uzročnom funkcijom. ${ }^{6} \mathrm{O}$ njegovom ranom pojavljivanju govori i činjenica da izraz nije bio shvatan bukvalno kod govornika. Naime, poznato je da je predlog per najjasnije izražavao cilj, a ne predlog $a$. Međutim, u slučaju veznika situacija je suprotna, pa je acciò che osnovni finalni veznik, dok je perché, pored per ciò che, osnovni uzročni veznik s daleko manje učestalom finalnom upotrebom. ${ }^{7}$ Finalna funkcija vezničkog izraza acciò che, dakle, ne proizlazi iz funkcija predloga $a$ : to je funkcija koja je nasleđena sa izrazom i nezavisna je od značenja elemenata koji ga sačinjavaju ${ }^{8}$ (Novellino LXIII: Il Soldano vi manda questo, acciocché voi non siate a piede). U prvim tekstovima che se obično pisalo odvojeno od acciò, tako da je, u slučajevima koordinacije dve finalne rečenice, u drugoj moglo da stoji samo che (CV I VIII 13: acciò che nel dono sia la sua vertù, la quale è liberalitade e che essa si possa in esso notare, allora si conviene esser netto d'ogni atto di mercatantia).

Acciò che je najrasprostranjeniji finalni veznik u staroitalijanskim tekstovima (Salvi, Renzi, 2010: 1091) i glavni finalni veznik u 13. i 14. veku (D’Arienzo, Frenguelli, 2012: 371). Rečenice koje je uvodio ovaj veznik mogle su da stoje u bilo kom položaju: ispred ili iza nadređene, ili kao umetnuta (Decameron I In 43: E acciò che dietro ad ogni particularità le nostre passate miserie per la città avvenute più ricercando non vada, dico che così inimico tempo correndo per quelle, non per ciò meno d'alcuna cosa risparmiò il circustante

$6 \quad$ Vremenom acciò che biva sve više upotrebljavan veznik u finalnoj funkciji. Hronološki posmatrano, uzročna vrednost ustupa mesto finalnoj tako da u Noveli$n u$ od petnaest pojavljivanja, šest su s finalnom a devet sa uzročnom funkcijom; u Danteovom Novom životu veznik se pojavljuje sedam puta sa uzročnom, a dva puta više s finalnom vrednošću; konačno, u Dekameronu, acciò che se koristi isključivo s finalnom funkcijom. Ovi podaci ukazuju na progresivnu specijalizaciju veznika ka finalnoj vrednosti (D'Arienzo, Frenguelli, 2012: 371).

7 Pored finalne, u starom jeziku, acciò che je imalo i uzročnu vrednost. Međutim, stroga razlika je pravljena upotrebom načina, tako da je u namernim rečenicama uvek stajao glagol u konjunktivu (up. Novellino XLIX: E dissero intra loro: di costui avremo noi grande mercato. Acciò che sembiava loro anzi povero che ricco).

8 Sličan je slučaj s vezničkim izrazom $a$ che / acché koji se koristio krajem XIX veka, a koji isto tako ima finalnu vrednost. 
contrado; Novellino LXIII: Lo re fu savio: fecevi montare su un suo scudiere, acciocché il provasse; Novellino XCII: Il più principale nella malizia, acciò che il fatto non s'indugiasse, andò là). Kasnije je počela da se koristi i varijanta acciò (bez veznika che), ali nije uspela da nadvlada prvobitni oblik (Vasari I 144: Lavorando la massa della materia in su quel che è umido, fa maggior presa, bagnando di continuo dove lo stucco si mette, acciò si renda più facile a lavorarlo; Machiavelli VII 2: Come intervenne a molti in Grecia nelle città di Ionia e di Ellesponto, dove furono fatti principi da Dario, acciò le tenessino per sua sicurtà e gloria; Verga 1 28: La povera fanciulla [...] andò a lavorare due giorni nel campo del curato, acciò dicesse la messa per la sua morta il primo lunedi del mese). U savremenom jeziku varijanta bez che nije više u upotrebi, a ulogu i učestalost vezničkog izraza acciò che zamenio je veznik affinché. I dalje se koristi, ali isključivo u književnom registru, pri čemu se, ipak, njegovom upotrebom pripovedanju daje arhaičan ton.

Perciò che (i varijanta per ciò che). Però che. Pored acciò che, perciò che bio je jedan od najzastupljenijih uzročnih veznika u starom jeziku, posebno kod Bokača. Poput perché, mogao je imati i finalnu vrednost, uz obaveznu upotrebu konjunktiva (Decameron II 9 14: E perciò che tu non creda che noi [...] crediamo avere altra moglie [...], voglio un poco con teco sopra questa materia ragionare; Decameron III 7 24: Io so bene quale egli è, né ve ne domanderò per saperlo meglio, ma per ciò che voi medesima dicendolo n'abbiate più rimordimenro). U Novelinu, međutim, nije prisutna ova vrednost veznika perciò che. Izraz però che takođe je povremeno imao jasno finalnu vrednost (CV II I 1: Ma però che più profittabile sia questo mio cibo, prima che vegna la prima vivanda voglio mostrare come mangiare si dee; PD XI 31: La provedenza [...] / però che andasse ver'lo suo diletto / la sposa [...] / due principi ordinò in suo favore). Prolektički položaj rečenice koju uvodi veznički izraz pojačava konotaciju iščekivanja radnje nadređene rečenice, a potvrdu o finalnoj vrednosti daje i dosledna upotreba konjunktiva u podređenoj rečnici. Ovi veznički izrazi ne korise se u savremenom jeziku.

Sì che. U staroitalijanskom zabeležili smo upotrebu sì che $(s i c+c h e) \mathrm{s}$ posledično-finalnom vrednošću s predikatom podređene rečenice u konjunktivu (Novellino XXV: Posesi in cuore di volere tutto dispendere alla vita sua, sì che non rimanesse il suo dopo lui). U savremenom jeziku ovaj izraz jeste dominantno posledični.

Acché (a che) bio je rasprostranjen veznik krajem 19. veka (Pascoli 410: Si fanno / cipelle, acché tu con la moglie accanto / ne mangi all'alba, 
il primo di dell'anno; Svevo 3-680: Dopo di aver provveduto acché la mia tomba fosse tenuta in pieno ordine) kada je doživeo kritiku savremenenih gramatičara (Fanfani-Arlia, 1881:9 i Fornaciari, 1881:377). Danas je ovaj oblik gotovo izašao iz upotrebe; nalazimo ga samo sporadično, na primer $\mathrm{u}$ pravno-administrativnom registru (Costituzione italiana, art. 30: Nei casi di incapacità dei genitori, la legge provvede a che siano assolti i loro compiti).

Affinché je finalni veznik novijeg doba. Kao prvi primer zabeležene upotrebe, Salvi, Renzi (2010: 1091) i etimološki rečnici navode 1348. godinu i citat iz Hronike Đovanija Vilanija: E il primo giorno fece passare la reina con ogni gente di mestiere e con parte degli arnesi dell'oste; il secondo di passò il re con tutta sua gente, salvo ch'a cautela di guerra lasciò in aguato di fuori da Messina due capitani con MM cavalieri, a.ffine che levata l'oste, se quegli di Messina uscissono fuori per guadagnare della roba del campo, venissono loro adosso e entrassono nella terra, dok D’Arienzo, Frenguelli (2012: 373) pronalaze još jedan stariji primer u poeziji s kraja 13. veka (Guittone d'Arezzo, Rime, 1294): E voi, amico, a cui intendo faccia / bisogno assalto d'ogni parte, chere / vostro valor vedere, / e che val sapienzia / u'non è pazienzia, / e vol d'onor de prode e de piacere / secondo el valimento / de catun ben pagare. / Piacciavi di forzare; / e valor e talento, non bon cominciamento, / tornano a fin ch'apiacenti e a Dio piaccia. Nikada nije uspeo da u većoj meri prodre u govorni jezik. Ima isključivo finalno značenje (koje je jasno sadržano u samom obliku: $a+f-$ $n e+c h e)$ i stoga je u prednosti u odnosu na ostale, ionako malobrojne finalne veznike, pre svega perché. Koristi se u pisanom jeziku i karakteriše uzvišeni stil (Bembo I 93: Questa vita che noi viviamo, affine che noi bene operiamo c'è data; Tommaseo 4 361: Lodava i pregi altrui affinché della lode cadesse una stilla sui proprii; Eco 77: I porcai rimestavano [...] il sangue dei porci appena sgozzati, affinché non si coagulasse).

\section{Zaključak}

Iz analize korpusa zaključuje se, dakle, da u prvim dokumentima na narodnom jeziku nije postojao nijedan autentični finalni veznik. Svi veznici, a bilo ih je izuzetno malo (sedam: che, come, onde, perché, acciò che, perciò che, sì che) pored finalnosti mogli su da izražavaju i neki drugi logički odnos, pre svih odnos uzročnosti. Tek docnije, nastankom veznika affinché dobijen 
je prvi i, praktično, jedini veznik u italijanskom jeziku sa isključivo finalnom vrednošću. U kasnijim epohama nastali su i finalni veznički izrazi (allo scopo che, coll' (nell') intenzione che, a far si che) koji su u upotrebi i u savremenom italijanskom jeziku, ali izuzetno retko. Danas su, pored veznika affinché, u opštoj upotrebisamo oblici ché i perché, dok su acciocché, a che i onde stilski obeleženi, imaju arhaičan prizvuk i mogu se pronaći isključivo u pisanim formama (književnim delima ili kancelarijskom jeziku). Iz upotrebe su odavno izašli oblici perciò che, percò che, sì che (s finalnom vrednošću). Dakle, svođenje sistema finalnih veznika na praktično tri oblika u skladu je sa opštim tendencijama u razvoju italijanskih veznika. „Osiromašenje” vezničkog sistema u savremenom jeziku u suštini jeste posledica težnje jezika ka ekonomičnosti i u skladu je sa sličnim pojavama prisutnim i kod drugih kategorija reči. ${ }^{9}$ Ipak, broj finalnih veznika nekoliko puta je manji u odnosu na „srodnu” kategoriju uzročnih veznika. Ovu činjenicu protumačićemo većom zastupljenošću implicitnih oblika rečenica koje kao vezivni element koriste neki predlog (per, $a, d i$, $d a$ ), kao i neminovnom upotrebom konjunktiva u eksplicitnom obliku, načina koji se direktno vezuje za semantičku dimenziju ciljne rečenice.

\section{Literatura}

Ageno Brambilla, F. (1978). Congiuntivo. In Enciclopedia Dantesca (pp. 23362). Roma: Istituto della Enciclopedia Italiana.

Agostini, F. (1978). Proposizioni subordinate. In Enciclopedia Dantesca (pp. 370-408). Roma: Istituto della Enciclopedia Italiana.

Berretta, M. (1984). Connettivi testuali in italiano e pianificazione del discorso. In L. Coveri (ed), Linguistica testuale (pp. 237-254). Roma: Bulzoni.

Bertuccelli Papi, M. (1991). Le frasi finali. In L. Renzi, G. Salvi (eds), Grande grammatica italiana di consultazione (pp. 818-25). Bologna: Il Mulino.

D’Arienzo, M., Frenguelli, G. (2012). Le proposizioni finali. In M. Dardano (ed), Sintassi dell'italiano antico. La prosa del Duecento e del Trecento (pp.360-80). Roma: Carocci.

Fanfani, P., Arlia, C. (1881). Lessico dell'infima e corrotta italianità. Milano: Paolo Carrara.

9 Tako se, na primer, nekoliko oblika trećeg lica množine perfekta (scrissono, scrissoro, scrissero) svelo na jedan oblik (scrissero), broj due imao je nekoliko oblika (dui, duo, dua) itd. 
Fornaciari, R. (1881). Sintassi italiana dell'uso moderno. Firenze: Sansoni.

Greco Bolli, G. (1982). La funzione della finale nell'italiano scritto contemporaneo. Annali dell'Università per stranieri di Perugia, II, 131-158.

Herczeg, G. (1972). Saggi linguistici e stilistici. Firenze: Olschki.

Kristal, D. (1988). Enciklopedijski rečnik moderne lingvistike. Beograd: Nolit.

Mancarella, G. B. (1978). Linguistica romanza. Bologna: Zanichelli.

Pantiglioni, M. (2010). LE FRASI FINALI. In G. Salvi, L. Renzi (eds),GRAMMATICA DELL'ITALIANO ANTICO (pp. 1086-94). Bologna: Il Mulino.

Prandi, M. (1995). Le proposizioni finali in italiano: uno studio di grammatica filosofica. Cuadernos de filologia italiana, 2, 45-73.

Prandi, M., Gross, G., De Santis, C. (2005). LA FINALITÀ. STRUTTURE CONCETTUALI E FORME DI ESPRESSIONE IN ITALIANO. Firenze: Olschki.

Renzi, L., Salvi, G. (eds) (1991). Grande grammatica italiana di consultazione. Bologna: Il Mulino.

Rombi, M., Policarpi, G. (1985). Mutamenti sintattici nell'italiano contemporaneo: il sistema delle congiunzioni. In L. Agostiniani, P. Bellucci Maffei, M. Paoli (eds), Linguistica storica e cambiamento linguistico (pp. 225-244). Roma: Bulzoni.

Samardžić, M. (2003). Sintaksa i semantika veznika. Razvoj vezničkog sistema u italijanskom jeziku. Beograd: Filološki fakultet.

Serianni, L. (1988). Grammatica italiana. Italiano comune e la lingua letteraria. Torino: Utet.

Tekavčić, P. (1972). Grammatica storica dell'italiano. 3 voll. Bologna: Il Mulino.

Vagni, F. (1974). La proposizione finale nell'italiano contemporaneo. In M. Medici, A. Sangregorio (eds), Fenomeni morfologici e sintattici nell'italiano contemporaneo (pp. 329-337). Roma: Bulzoni.

\section{Izvori}

Ariosto, L. (1964). Orlando Furioso. Milano: Garzanti.

Battaglia, S. (1961-2001). Grande dizionario della lingua italiana. Torino: Utet. Benni, S. (2001). Dottor Niù. Milano: Feltrinelli.

Boccaccio, G. (1976). Decameron. Milano: Mondadori.

Cellini, B. (1958). La vita. Milano: Longanesi.

Eco, U. (1980). Il nome della rosa. Milano: Bompiani.

Enciclopedia Dantesca (1976). Roma: Istituto dell'Enciclopedia Italiana, Treccani. 
Favati, G. (ed) (1970). Il Novellino. Genova: Bozzi. Machiavelli, N. (1955). Il Principe. Torino: Einaudi. Pascoli. G. (1956). Poesie. Milano: Garzanti. Petrarca, F. (1974). Canzoniere. Milano: Garzanti. Verga, G. (1943). Tutte le novelle. Milano: Garzanti. Villani, G. (1991). Cronica. Torino: Einaudi.

Mila Samardžić

\section{Riassunto \\ SULLE ORIGINI E LO SVILUPPO DELLE CONGIUNZIONI FINALI IN ITALIANO}

Il presente contributo si propone di offrire, in una prospettiva diacronica, un quadro generale delle origini e dello sviluppo del sistema delle congiunzioni finali italiane. L'obiettivo del contributo è di verificare se il percorso di questa categoria di congiunzioni sia in conformità alle tendenze generali del sistema congiunzionale italiano. La lingua italiana ha ereditato solo una piccola parte del sistema latino delle congiunzioni ed ha ricreato la grande maggioranza delle congiunzioni. La lingua elaborata dagli autori del Due e del Trecento ha arricchito l'inventario delle congiunzioni sia dal punto di vista morfosintattico che da quello semantico. A partire dal Rinascimento il sistema ha cominciato a semplificarsi e uniformarsi. È un processo ancora in atto. La ricerca è stata effettuata in base al corpus costituito dalle opere letterarie dalle origini ai nostri giorni. Con particolare attenzione è stata osservata l'espansione del sistema nel Due, Tre e Cinquecento, periodi chiave per il generale sviluppo della lingua italiana. I risultati della ricerca hanno dimostrato che lo sviluppo del sistema delle congiunzioni finali in gran parte coincide con il quadro generale. Tuttavia rivela una particolarità quantitativa nel senso che il sistema dispone di un numero ridotto delle unità e inferiore alla media e riscontra una frequenza molto più bassa in confronto alle congiunzioni causali, concessive, condizionali o consecutive.

Parole chiave: congiunzioni, finalità, causalità, italiano, sintassi, diacronia. 